\title{
Thermal parameters determination of Co-Al-W as-cast alloy homogenization by DTA analysis
}

\author{
Agnieszka Tomaszewska ${ }^{1} \cdot$ Grzegorz Moskal $^{1} \cdot$ Damian Migas $^{1} \cdot$ Marta Mikuśkiewicz $^{1}$ (D) Tomasz Maciąg $^{2}$
}

Received: 1 December 2017 / Accepted: 27 May 2018/Published online: 9 June 2018

(C) The Author(s) 2018. This article is published with open access at Springerlink.com

\begin{abstract}
The $\gamma-\gamma^{\prime}$ Co-based superalloys are newly developed class of refractory alloys which may replace commercial Ni-based superalloys owing to their favorable properties at high temperature. In case of new Co-based superalloys, the heat treatment aims to obtain microstructure composed of appropriate volume fraction of small cuboidal $\gamma^{\prime}-\mathrm{Co}_{3}(\mathrm{Al}, \mathrm{W})$ precipitates within the $\gamma$-Co matrix. However, due to a high tendency to interdendritic segregations of alloying elements, the alloys based on Co-Al-W system should be normally homogenized before further steps of heat treatment (solutionizing and aging). In this study, thermal analysis was applied for determination of temperature range for primary heat treatment of the Co-9Al-9W (at.\%). The differential thermal analysis (DTA) measurements were carried out on the thermal analyzer NETZSCH STA 449 F3 Jupiter. On the base of obtained results, respectively, solvus of $\gamma^{\prime}$ phase and solidus temperatures were determined, as well as the thermal range of $\mathrm{Co}_{3} \mathrm{~W}\left(\mathrm{DO}_{19}\right)$ phase precipitation. As a consequence, the heat treatment without homogenizing (only solution and aging) was proposed as a most suitable way to obtain beneficial microstructure.
\end{abstract}

Keywords Co-Al-W alloy $\cdot$ DTA $\cdot$ heat treatment $\cdot \gamma^{\prime}$ solvus $\cdot \mathrm{DO}_{19}$ phase

\section{Introduction}

The successional advancement of superalloys over decades has been driven by continuous improvement in performance and efficiency of gas turbines in aircraft and power generation industries [1]. Owing to remarkable mechanical properties and oxidation resistance at high temperature, $\mathrm{Ni}$ based superalloys are commonly used materials for hightemperature applications such as turbine blades and disks in aircraft engines and industrial steam turbines [2, 3]. In general, conventional Co-based superalloys possess superior corrosion resistance; however, they exhibit lower mechanical properties in comparison with those of $\gamma^{\prime}$ -

Marta Mikuśkiewicz

marta.mikuskiewicz@polsl.pl

1 Institute of Materials Engineering, Faculty of Materials Engineering and Metallurgy, Silesian University of Technology, Krasińskiego 8 str., 40-019 Katowice, Poland

2 Department of Extraction Metallurgy and Environment Protection, Faculty of Materials Engineering and Metallurgy, Silesian University of Technology, Krasińskiego 8 str., 40-019 Katowice, Poland strengthened Ni-based superalloys; hence, these alloys are used for mechanically lower loaded gas turbine vanes, where appropriate performance in corrosive environments is required [4]. The material solution based on combination of the corrosion resistance and mechanical properties of these two groups of alloys would be admirable in view of the aircraft industry development.

This solution has become the fact in 2006; Sato et al. discovered the occurrence of $\gamma-\gamma^{\prime}$ microstructure in $\mathrm{Co}-$ $\mathrm{Al}-\mathrm{W}$ system [5]. Unlike $\mathrm{Ni}_{3} \mathrm{Al}, \mathrm{Co}_{3} \mathrm{Al}$ phase does not exist in the binary $\mathrm{Co}-\mathrm{Al}$ phase diagram [6], whereas the addition of $\mathrm{W}$ leads to precipitation of an ternary compound with the stoichiometry $\mathrm{Co}_{3}(\mathrm{Al}, \mathrm{W})$ in fcc $\gamma$-Co matrix after appropriate heat treatment. The coexistence of $\gamma$-Co matrix in equilibrium with $\mathrm{L}_{2}$ ordered $\gamma^{\prime}-\mathrm{Co}_{3}(\mathrm{Al}, \mathrm{W})$ phase is attainable owing to an appropriate lattice misfit, required in the case of $\gamma / \gamma^{\prime}$ microstructure [3]. Furthermore, these alloys have been developed in order to improve ductility and high-temperature capability by the addition of minor alloying elements such as $\mathrm{B}, \mathrm{Ta}, \mathrm{Nb}, \mathrm{Mo}, \mathrm{Hf}$ and $\mathrm{Ti}$ [7-11]. Moreover, these additions strengthen the grain boundary [11-14] or modify the volume fraction of $\gamma^{\prime}$ [15]. Shinagawa et al. [16] reported the increase in $\gamma^{\prime}$-phase 
fraction in the $\mathrm{Co}-\mathrm{Al}-\mathrm{W}$ system with increasing content of $\mathrm{Ni}$. This phenomenon may permit for higher amount of alloying elements, such as $\mathrm{Cr}$, without deterioration of stability of the $\gamma^{\prime}$-phase [17]. Moreover, the differential scanning calorimetry (DSC) measurements showed increase in the $\gamma^{\prime}$-solvus temperature with Ni content [16].

Generally, the analyzed group of alloys is relatively new and still insufficiently described in the literature, practically in all technological and research aspects. The studies concerning influence of various alloying elements on microstructure of new cobalt-based superalloys and the $\gamma^{\prime}$ stability were mentioned above. Moreover, there the investigations regarding mechanical properties of these alloys at elevated temperature and oxidation resistance are available as well [18-22].

One of the most interesting problems related to the discussed alloys is determination of thermal parameters of heat treatment which usually included homogenization, solution heat treatment and aging in order to form and widen the $\gamma^{\prime}$ fraction within the $\gamma$-Co matrix. The basic role of homogenization is decreasing differences in chemical composition of alloy, especially in interdendritic areas. The role of another step is related to formation of desirable $\gamma / \gamma^{\prime}$ double-phase microstructure. Similarly to Ni-based superalloys, Co-based materials exhibit strong tendency to formation of deleterious phases such as $\mathrm{Co}_{3} \mathrm{~W}$ with $\mathrm{DO}_{19}$ structure. This problem is significant and should be considered in design of parameters of the heat treatment.

The aim of following paper is introduction to the heat treatment of new Co-Al-W cobalt-based superalloys and identification of homogenization/solutionizing necessity. The most beneficial process which provides both redistribution of alloying elements and the preparation of microstructure to aging process will be chosen.

\section{Materials and methods}

The Co-9Al-9W (at.\%) alloy was melted using induction vacuum furnace VSG 02 Balzers and casted under $\mathrm{Ar}$ atmosphere. The modified technique of melting was utilized due to technological difficulties connected with homogenization of W-rich alloys [23], caused by segregation of this element. Before the melting, a chamber of furnace was three times washed by Ar blowing, then the pressure inside was reduced to value of $0.13 \mathrm{~Pa}$, and subsequently the chamber was gas-filled to pressure $80 \mathrm{kPa}$. Pure metals were used in investigation, including Co ( $\mathrm{min}$. 99.98\%), Al (99.98\%) and W (99.98\%), which was added with $20 \%$ excess to nominal composition, due to its form (pellet). W pellet was being dosed to liquid solution of $\mathrm{Co}$ and $\mathrm{Al}$ after its homogenization. The $\mathrm{Co}-\mathrm{Al}-\mathrm{W}$ alloy was melted in temperature range $1650-1750{ }^{\circ} \mathrm{C}$ in time of approx. $10 \mathrm{~min}$. Investigated alloy was casted into cold graphite molds under protective gas (Ar).

The rods of size $\varnothing 20 \times 100 \mathrm{~mm}$ were final product of casting. The nominal and measured chemical composition of as-cast alloy is presented in Table 1. For proper choice of heat treatment parameters, the thermal analysis including differential thermal analysis (DTA) was carried out. The DTA analysis was carried out using NETZSCH STA 449 F3 Jupiter thermal analyzer. The temperature range of analysis was $40 / 1500{ }^{\circ} \mathrm{C}$ of heating rate $10{ }^{\circ} \mathrm{C} \mathrm{s}^{-1}$. The utilized protective gas was argon with flow rate of $30 \mathrm{~mL} \mathrm{~min}{ }^{-1}$. The utilized model was $\alpha-\mathrm{Al}_{2} \mathrm{O}_{3}-$ synthetic sapphire.

Afterward, the metal pieces were cut from ingot; samples for heat treatment investigations were prepared. Solution heat treatment was performed using different combinations of parameters (1300 and $1350{ }^{\circ} \mathrm{C}$ for 5 and $24 \mathrm{~h}$, respectively). Solutionized specimens were subsequently aged in furnace environment at 900 and $950{ }^{\circ} \mathrm{C}$ in temperature range $1-10 \mathrm{~h}$. Both solution heat treatment and aging were carried out in vacuum furnace; the Ar protection was utilized.

In further part of evaluation, the phase composition of as-cast alloy and alloy after annealing operations was examined using $\mathrm{X}^{\prime} \mathrm{Pert}^{3}$ Powder XRD system. Chemical composition and microstructure of alloy after solution heat treatment and aging were evaluated by means of scanning electron microscopy (SEM) and energy-dispersive spectroscopy (EDS) using Hitachi S-4200.

\section{Results and discussion}

Primary microstructure was the first factor taken into consideration before heat treatment investigations. Detailed analysis of the microstructure of as-cast Co-9Al-9W (at.\%) alloy is presented by authors in the other study [24]. The high homogeneity of primary microstructure in view of alloying elements' distribution may be the reason of potential avoidance of additional homogenization heat treatment; hence, only solutionizing and aging were taken into account and carried out. However, this high level of homogeneity may be only local effect, such that

Table 1 Chemical composition of Co-9Al-9W alloy cast used in investigation

\begin{tabular}{llll}
\hline Nominal composition/at.\% & \multicolumn{3}{l}{ Measured chemical composition/at.\% } \\
\cline { 2 - 4 } & Co & Al & W \\
\hline Co-9Al-9W & 81.7 & 9.1 & 9.2 \\
\hline
\end{tabular}


determination of thermal parameters of homogenization should be performed.

The key for heat treatment considerations was DTA curve of investigated alloy (Fig. 1). The DTA plot related to heating process exhibits characteristic distinct endothermic effect below $1000{ }^{\circ} \mathrm{C}$ (area "A"). Detailed observations of first derivative (Fig. 1b) indicated that previously mentioned effect started at $976{ }^{\circ} \mathrm{C}$ with its maximum at $1020{ }^{\circ} \mathrm{C}$ and end at ca. $1050{ }^{\circ} \mathrm{C}$. Moreover, a low peak which started at $956{ }^{\circ} \mathrm{C}$ was noticed. This temperature range of main observed thermal effect is corresponding to the $\gamma^{\prime}$ dissolution (loosing of ordered structure), according to the literature data $[5,25,28]$. Additional peak at temperature $956{ }^{\circ} \mathrm{C}$ may be related to a local inhomogeneity of $\mathrm{Al}$ and $\mathrm{W}$ concentration. The lower concentration of Al may be connected with the presence of the $\mathrm{Co}_{3} \mathrm{~W}$ phase of $\mathrm{DO}_{19}$ type [29]. Furthermore, the thermal analysis showed endothermic effect connected with melting, which started at $1447{ }^{\circ} \mathrm{C}$.

First derivative of cooling curve (Fig. 1c) showed exothermic effect connected with solidifying of molten alloy, which implies solidification of examined superalloy at $1487{ }^{\circ} \mathrm{C}$. Furthermore, two concave peaks at lower temperatures were observed. The first one started at
$1005{ }^{\circ} \mathrm{C}$ with maximum at $985{ }^{\circ} \mathrm{C}$. This effect is believed to be connected with first endothermic effect observed in heating curve analysis and may reveal start of $\mathrm{Co}_{3}(\mathrm{Al}, \mathrm{W})$ precipitation in $\gamma \rightarrow \gamma^{\prime}$ process [29]. Another exothermic effect occurred in temperature range $875-865{ }^{\circ} \mathrm{C}$, where the undesirable $\mathrm{Co}_{3} \mathrm{~W}$ participation was observed [29].

Taking into account melting start temperature (solidus at $1447{ }^{\circ} \mathrm{C}$ ) and temperature $1005^{\circ} \mathrm{C}$, which is believed to be temperature of start of the $\gamma^{\prime}$ dissolution during cooling process, the schematic of transition temperatures in $\mathrm{Co}-$ 9Al-9W (at.\%) alloy was prepared (Fig. 2). The thermal effects related to $\mathrm{Co}_{3} \mathrm{~W}$ phase precipitation imply that homogenization process with relatively low cooling rate exhibit deleterious effect in the form of $\mathrm{DO}_{19}$ phase formation. Much more beneficial microstructure will be expected in case of only solutionizing treatment with next aging, without homogenization process after casting.

As a consequence, the solutionizing window was determined and is shown in Fig. 2, where temperature ranges of possible solution heat treatment and aging operations were chosen in temperature range $1050-1375{ }^{\circ} \mathrm{C}$ (maximum temperature from Fig. 1b, where no significant thermal effects were observed). Temperatures 1300 and $1350{ }^{\circ} \mathrm{C}$ were chosen as potential
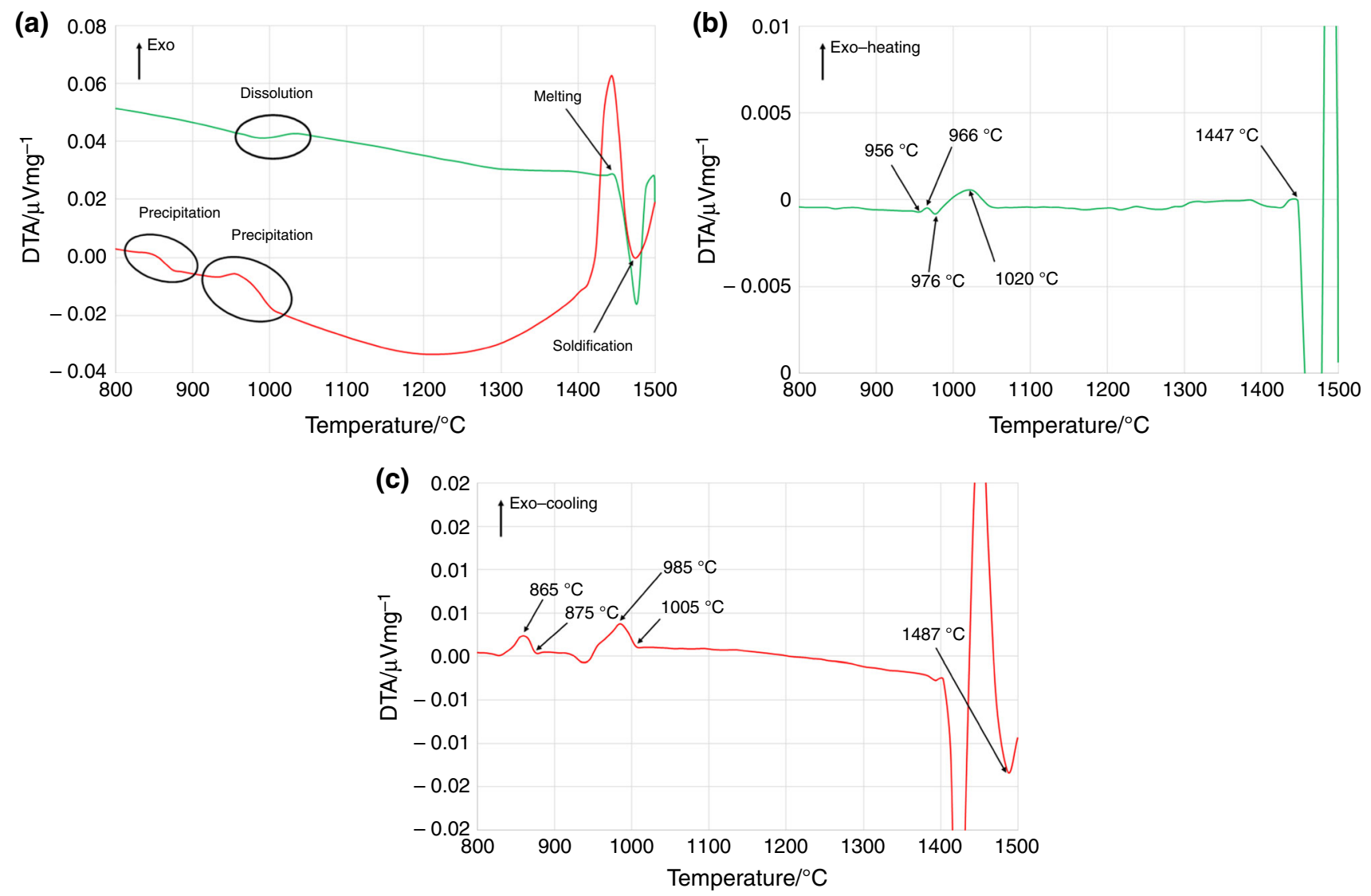

Fig. 1 a-c Differential thermal analysis (DTA) of as-cast Co-9Al-9W alloy 
Fig. 2 Schematic of transition temperatures in $\gamma-\gamma^{\prime} \mathrm{Co}-9 \mathrm{Al}-$ $9 \mathrm{~W}$ alloy

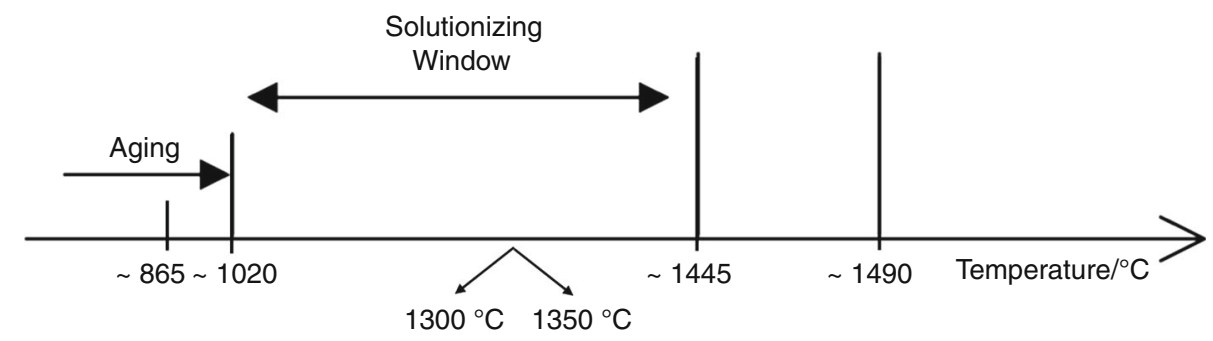

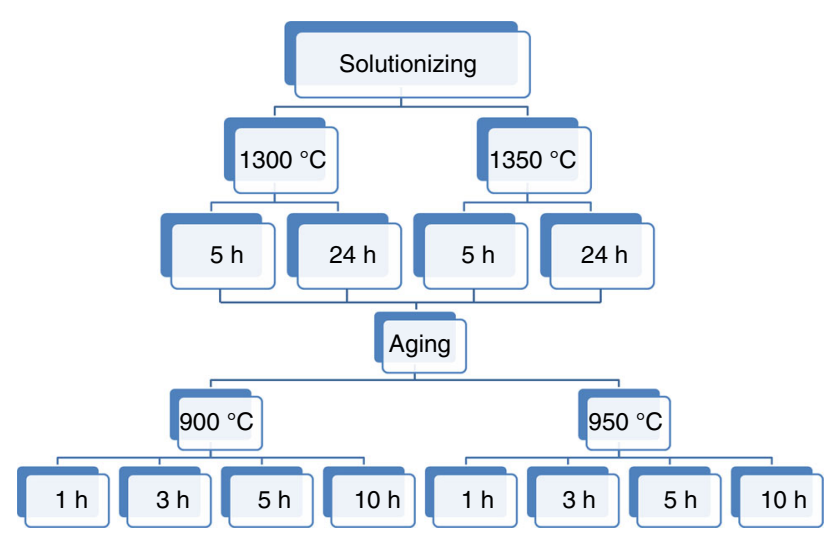

Fig. 3 Diagram showing applied combinations of solution heat treatment and aging temperatures of solutionizing, aiming to obtain supersaturated solid solution. Furthermore, the temperatures of aging were chosen as well, respectively, 900 and $950{ }^{\circ} \mathrm{C}$. The scheme including combinations of solution heat treatment and aging used in investigation are shown in Fig. 3.

Besides the temperature of heat treatment processes, another important factor is time of heat treating. The time of solution heat treatment was chosen, respectively, 5 and $24 \mathrm{~h}$. Taking into consideration the financial aspects, short time of solutionizing is more beneficial; however, it may not provide appropriate supersaturated solid solution, which is potentially easier to obtain after $24 \mathrm{~h}$ of annealing. Normally, the high temperature and long time of exposure may cause deleterious grain growth; however, these alloys
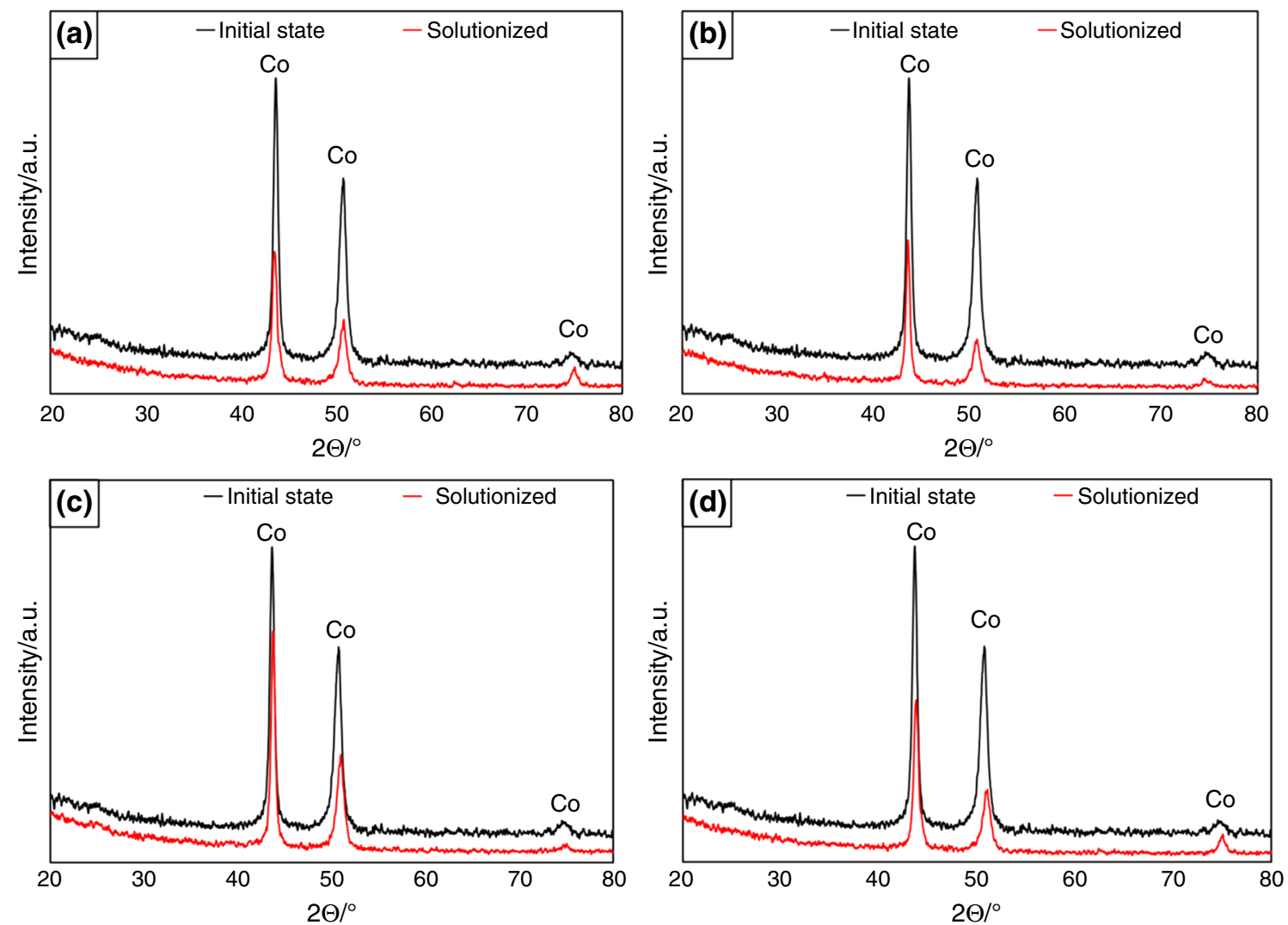

Fig. 4 X-ray diffraction results of Co-9Al-9W alloy: a solutionized at $1300{ }^{\circ} \mathrm{C}$ for $5 \mathrm{~h}$; b solutionized at $1300{ }^{\circ} \mathrm{C}$ for $24 \mathrm{~h}$; c solutionized at $1350{ }^{\circ} \mathrm{C}$ for $5 \mathrm{~h}$; d solutionized at $1350{ }^{\circ} \mathrm{C}$ for $24 \mathrm{~h}$ 

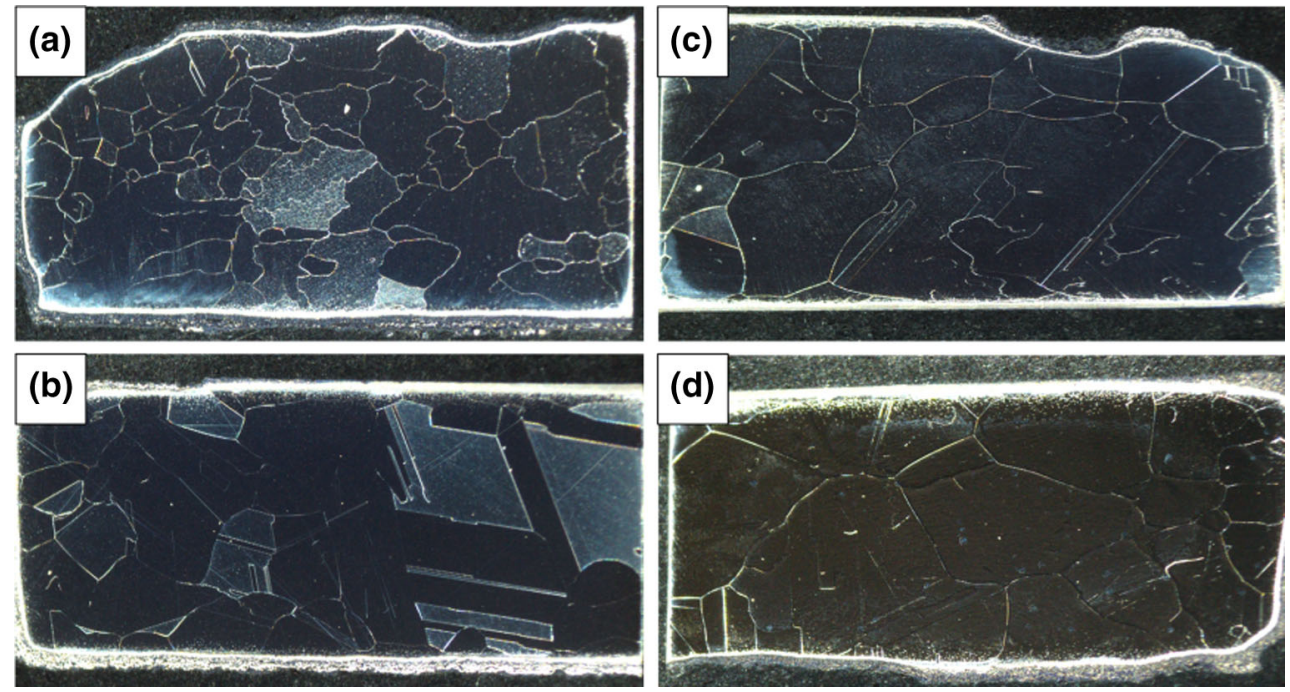

Fig. 5 Macrographs of Co-9Al-9W alloy specimens: a solutionized at $1300{ }^{\circ} \mathrm{C}$ for $5 \mathrm{~h}$; b solutionized at $1300{ }^{\circ} \mathrm{C}$ for $24 \mathrm{~h}$; c solutionized at $1350{ }^{\circ} \mathrm{C}$ for $5 \mathrm{~h}$; d solutionized at $1350{ }^{\circ} \mathrm{C}$ for $24 \mathrm{~h}$

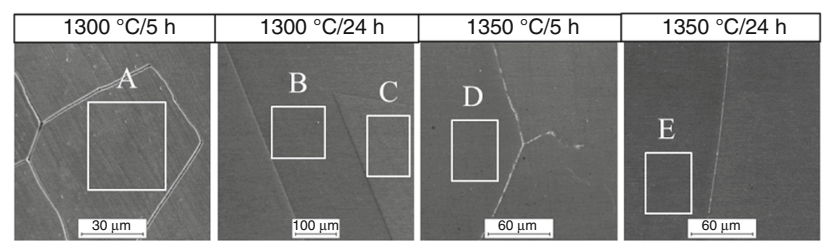

Fig. 6 SEM images of microstructure of Co-9Al-9W alloy after different variants of solution heat treatment, with marked areas for chemical composition analysis

are designated for elements working under creep conditions, and thus coarse grain structure is beneficial.

The X-ray diffraction patterns of $\mathrm{Co}-\mathrm{Al}-\mathrm{W}$ alloy in ascast state and after different variants of solutionizing are shown in Fig. 4. In initial state, the presence of one phase corresponding to solid solution of alloying elements in fcc cobalt matrix was detected. The XRD analysis of solutionized specimens was performed, and the results are shown as well. After each variant of solutionizing, no substantial changes excluding intensity of peaks were observed. No phases except of Co-based matrix were detected.

Figure 5 shows macrographs of specimens after solution heat treatment under different combinations of processing parameters. Coarse grains are observable in all macrographs, which is proof of substantial grain growth during solution annealing. SEM images of the microstructure of investigation alloy after solution heat treatment are shown in Fig. 6. In each case, the uniform coarse grain microstructure was obtained after solutionizing. The chemical composition analysis in micro-areas (Table 2) marked in Fig. 6 shows that investigated microstructures are chemically homogenous. The chemical composition
Table 2 Chemical composition of areas marked in Fig. 6

\begin{tabular}{llll}
\hline Area & \multicolumn{3}{l}{ Chemical composition/at.\% } \\
\cline { 2 - 4 } & Co & Al & W \\
\hline A & 82.9 & 8.1 & 9.0 \\
B & 82.5 & 8.4 & 9.1 \\
C & 82.8 & 8.1 & 9.1 \\
D & 82.3 & 8.3 & 9.4 \\
E & 83 & 7.9 & 9.1 \\
\hline
\end{tabular}

analyzed within all microstructures is relatively close to nominal chemical composition; however, slightly decreased content of $\mathrm{Al}$ was observed.

Afterward, the solutionized specimens were artificially aged at $900 / 950{ }^{\circ} \mathrm{C}$ for $1,3,5$ and $10 \mathrm{~h}$. Those treatment parameters were initially selected due to characterization of solutionizing temperature on the phase constituent after aging and determination of effect of solutionizing parameters and their effectiveness. For further investigations, the final aging parameters will be determined on the base of DTA curves of specimens after solutionizing at the most beneficial temperature. The examples of X-ray diffraction analysis of specimens solutionized at $1300{ }^{\circ} \mathrm{C}$ for 5 and 24 $\mathrm{h}$ and with aging $900 / 950^{\circ} \mathrm{C}$ for $1-10 \mathrm{~h}$ are shown in Fig. 7, as well as the examples of data for specimens solutionized at temperature $1350{ }^{\circ} \mathrm{C}$ for $5 \mathrm{~h}$ and aged at temperature $900 / 950{ }^{\circ} \mathrm{C}$ in time range from 1 to $10 \mathrm{~h}$. Present diffraction patterns in all cases showed peaks corresponding to $\gamma$-Co matrix and $\gamma^{\prime} \mathrm{Co}_{3}(\mathrm{Al}, \mathrm{W})$ precipitates. Obtained data are comparable to the available literature data [25-27]. Furthermore, the differences in XRD reflexes corresponding to $\gamma$ and $\gamma^{\prime}$ are not observable, which 

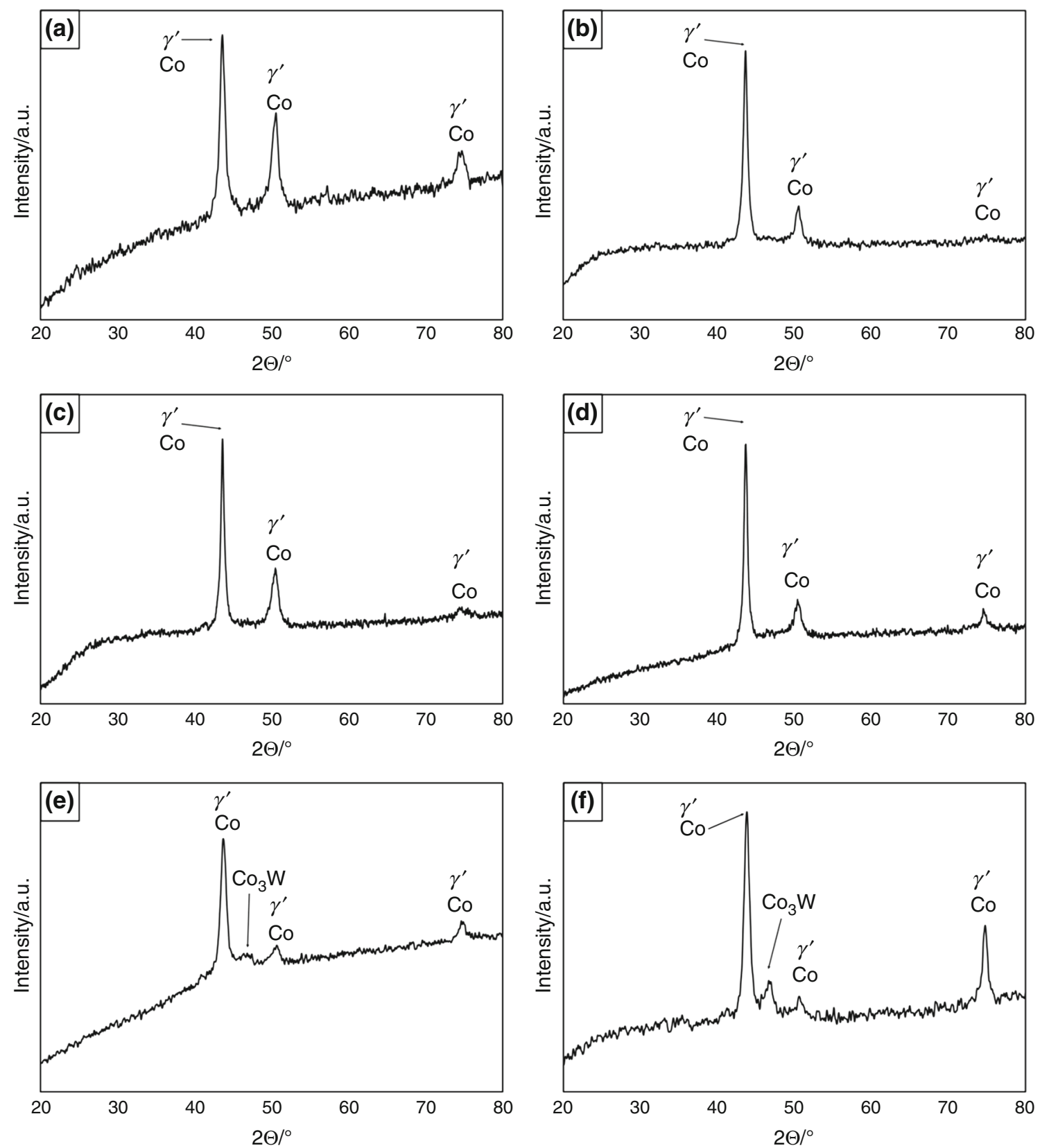

Fig. 7 X-ray diffraction results of Co-9Al-9W alloy: a solutionized at $1300{ }^{\circ} \mathrm{C}$ for $5 \mathrm{~h}$ and aged at $900{ }^{\circ} \mathrm{C}$ for $10 \mathrm{~h}$; b solutionized at $1300{ }^{\circ} \mathrm{C}$ for $5 \mathrm{~h}$ and aged at $900{ }^{\circ} \mathrm{C}$ for $10 \mathrm{~h}$; c solutionized at $1300{ }^{\circ} \mathrm{C}$ for $24 \mathrm{~h}$ and aged at $900{ }^{\circ} \mathrm{C}$ for $10 \mathrm{~h}$; d solutionized at

may imply very small lattice misfit between these phases, which is beneficial effect. However, the most important fact is that peak characteristic for $\mathrm{Co}_{3} \mathrm{~W}$ phase occurred after aging of specimens solutionized at $1350{ }^{\circ} \mathrm{C}$. The peak was observed after just $1 \mathrm{~h}$ of treatment in all cases of those variant of solutionizing. Observed peak and other reflexes corresponding to mentioned deleterious phase with $\mathrm{D} 0_{19}$ structure are characterized by low intensity; however, intensity was increasing with increasing aging time. This

$1300{ }^{\circ} \mathrm{C}$ for $24 \mathrm{~h}$ and aged at $950{ }^{\circ} \mathrm{C}$ for $10 \mathrm{~h}$; e solutionized at $1350{ }^{\circ} \mathrm{C}$ for $5 \mathrm{~h}$ and aged at $900{ }^{\circ} \mathrm{C}$ for $1 \mathrm{~h}$; f solutionized at $1350{ }^{\circ} \mathrm{C}$ for $25 \mathrm{~h}$ and aged at $900{ }^{\circ} \mathrm{C}$ for $1 \mathrm{~h}$

discovery requires further detailed investigations. However, previously described observation suggests that this temperature of solutionizing is not beneficial taking into account the phase composition.

The success of applied solution heat treatment at $1300{ }^{\circ} \mathrm{C}$ for 5 or $24 \mathrm{~h}$ and with aging aimed to obtain desired two-phase microstructure, showed by X-ray diffraction analysis which was confirmed by microstructural observations (Fig. 8). Each combination of 


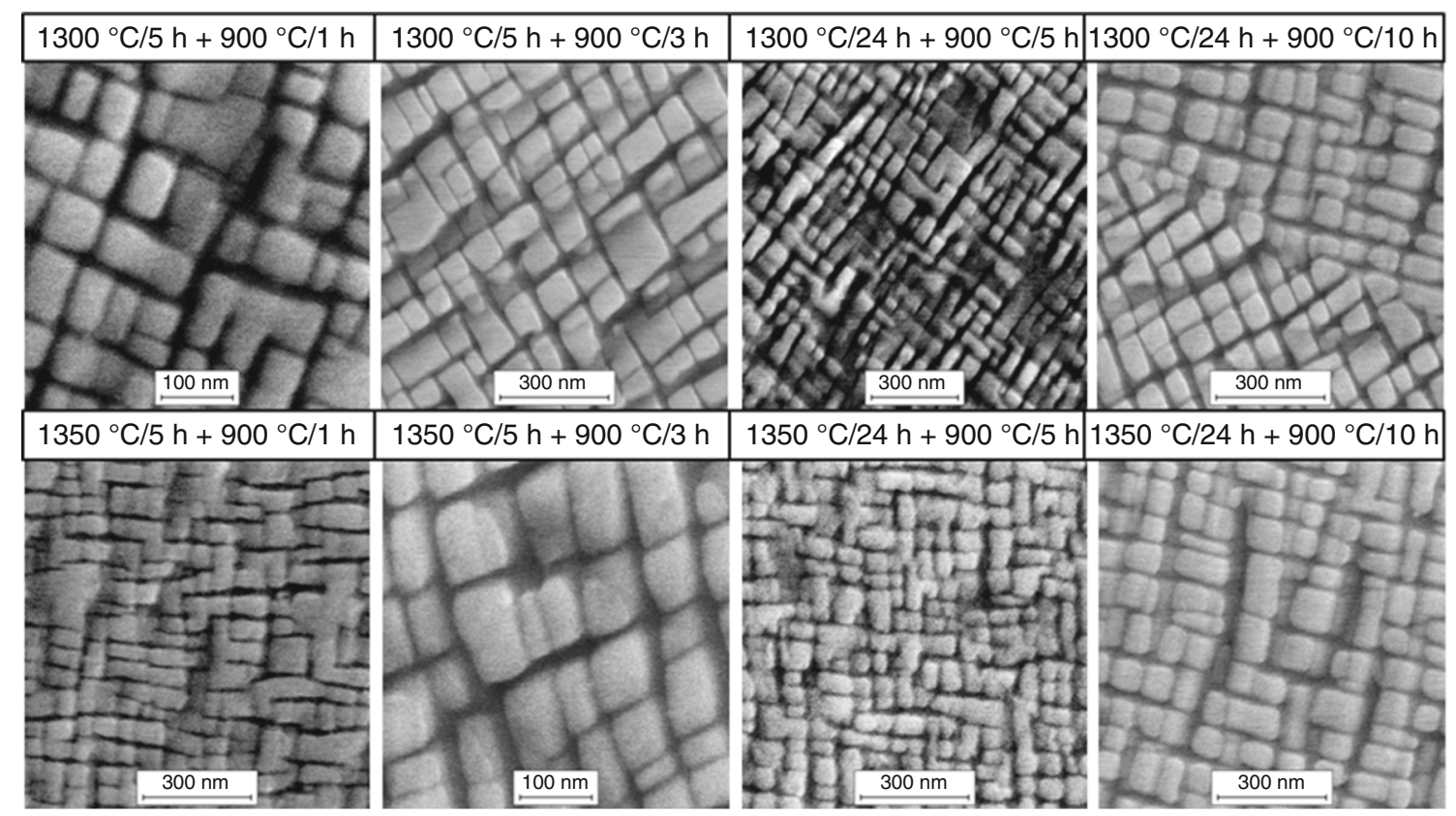

Fig. 8 SEM images of microstructure of Co-9Al-9W alloy after long-term annealing using different combinations of processing parameters of solution heat treatment and aging

solutionizing operations from $1300{ }^{\circ} \mathrm{C}$ resulted in microstructure composed of $\gamma$-Co matrix and ultra-fine cuboidal $\gamma^{\prime}$ precipitates, analogous to that of present in $\mathrm{Ni}-$ based superalloys.

\section{Conclusions}

The differential thermal analysis (DTA) was performed in order to determine transition temperatures in $\gamma-\gamma^{\prime} \mathrm{Co}-9 \mathrm{Al}-$ $9 \mathrm{~W}$ (at.\%) alloy, being base of investigations concerning heat treatment parameters determination. DTA studies showed distinct thermal effects corresponding to melting of alloy and $\gamma^{\prime}$ and $\mathrm{DO}_{19}$ phases dissolution/precipitation, which simplified the choice of precipitation hardening parameters design.

The X-ray diffraction analysis and microstructure observations were performed in order to evaluate the effects of performed solution heat treatment and aging. The XRD patterns after solutionizing and in initial state showed the differences in phase constituent of heat-treated alloy. In all cases, the solutionizing process revealed uniform monophase microstructure of $\gamma$ Co-based solid solution; however, aging treatment caused important changes based on formation of $\gamma / \gamma^{\prime}$ structure for specimens solutionized at $1300{ }^{\circ} \mathrm{C}$ and $\gamma / \gamma^{\prime} / \mathrm{DO}_{19}$ microstructure in the case of specimens solutionized at $1350{ }^{\circ} \mathrm{C}$.

The final suggestions with presented investigations revealed that the most favorable heat treatment of $\mathrm{Co}-9 \mathrm{Al}-$ $9 \mathrm{~W}$ alloy should be based on solutionizing treatment at temperature $1300{ }^{\circ} \mathrm{C}$ or similar, for time from 5 to $24 \mathrm{~h}$ with aging process at temperature range $900-950{ }^{\circ} \mathrm{C}$ for time from 1 to $10 \mathrm{~h}$. Due to formation of undesirable $\mathrm{DO}_{19}$ phase, the slow-cooled homogenization should be omitted.

Acknowledgements This work was supported by the National Science Centre, Poland, under Grant Number 2016/21/D/ST8/01687.

Open Access This article is distributed under the terms of the Creative Commons Attribution 4.0 International License (http://creative commons.org/licenses/by/4.0/), which permits unrestricted use, distribution, and reproduction in any medium, provided you give appropriate credit to the original author(s) and the source, provide a link to the Creative Commons license, and indicate if changes were made.

\section{References}

1. Liang Z, Yu M, Gui Y, Singh $\mathrm{P}$, Zhao Q. High temperature oxidation of superalloys in steam environment. In: Han Y, editor. High performance structural materials. CMC 2017. Singapore: Springer; 2018.

2. Condruz MR, Matache G, Paraschiv A, Puşcaşu C. Homogenization heat treatment and segregation analysis of equiaxed CMSX-4 superalloy for gas turbine components. J Therm Anal Calorimet. 2018;1-11.

3. Sims CT, Hagel WC. The superalloys. New York: Wiley; 1972.

4. Sims CT, Stoloff NS, Hagel WC. Superalloys II. New York: Wiley; 1987.

5. Sato J, Omori T, Oikawa K, Ohnuma I, Kainuma R, Ishida K. Cobalt-base high-temperature alloys. Science. 2006;312:90-1.

6. Baker H, Okamoto H. ASM Int. ASM Handbook. 1992;3:501.

7. Yan H-Y, Vorontsov VA, Dye D. Alloying effects in polycrystalline $\gamma^{\prime}$ strengthened $\mathrm{Co}-\mathrm{Al}-\mathrm{W}$ base alloys. Intermetallics. 2014;48:44-53. 
8. Ooshima M, Tanaka K, Okamoto NL, Kishida K, Inui H. Effects of quaternary alloying elements on the $\gamma^{\prime}$ solvus temperature of $\mathrm{Co}-\mathrm{Al}-\mathrm{W}$ based alloys with fcc/ $\mathrm{L}_{2}$ two-phase microstructures. J Alloys Compd. 2010;508:71-8.

9. Povstugar I, Choi PP, Neumeier S, Bauer A, Zenk CH, Goken M, Raabe D. Elemental partitioning and mechanical properties of Tiand Ta-containing Co-Al-W-base superalloys studied by atom probe tomography and nanoindentation. Acta Mater. 2014;78:78-85.

10. Feng G, Li H, Li SS, Sha JB. Effect of Mo additions on microstructure and tensile behavior of a Co-Al-W-Ta-B alloy at room temperature. Scripta Mater. 2015;67:499-502.

11. Meher S, Banerjee R. Partitioning and site occupancy of Ta and Mo in Co base $\gamma / \gamma^{\prime}$ alloys studied my atom probe. Intermetallics. 2014;49:138-42.

12. Bauer A, Neumeier S, Pyczak F, Göken M. Microstructure and creep strength of different $\gamma / \gamma^{\prime}$-strengthened Co-base superalloy variants. Scripta Mater. 2010;63:1197-200.

13. Shinagawa K, Omori T, Oikawa K, Kainuma R, Ishida K. Ductility enhancement by boron addition in $\mathrm{Co}-\mathrm{Al}-\mathrm{W}$ high-temperature alloys. Sciripta Mater. 2009;61:612-5.

14. Klein L, Von BB, Killian MS, Schmuki P, Virtanen S. The effect of grain boundaries on high temperature oxidation of new $\gamma$ 'strengthened $\mathrm{Co}-\mathrm{Al}-\mathrm{W}-\mathrm{B}$ superalloys. Corros Sci. 2014;79:29-33.

15. Xue F, Zhou HJ, Ding XF, Wang ML, Feng Q. Improved high temperature $\gamma^{\prime}$ stability of Co-Al-W-base alloys containing $\mathrm{Ti}$ and Ta. Mater Lett. 2013;112:215-8.

16. Shinagawa K, Omori T, Sato J, Oikawa K, Ohnuma I, Kainuma $\mathrm{R}$, Ishida K. Phase equilibria and microstructure on $\gamma^{\prime}$ phase in Co-Ni-Al-W system. Mater Trans. 2008;49:1474-9.

17. Klein L, Shen Y, Killian MS, Virtanen S. Effect of B and Cr on the high temperature oxidation behaviour of novel $\gamma / \gamma^{\prime}$-strengthened Co-base superalloys. Corros Sci. 2011;53:2713-20.

18. Klein L, Bauer A, Neumeier S, Goken M, Virtanen S. High temperature oxidation of $\gamma / \gamma^{\prime}$-strengthened Co-base superalloys. Corros Sci. 2011;53:2027-34.
19. Klein L, Virtanen S. Corrosion properties of novel $\gamma^{\prime}$-strengthened Co-base superalloys. Corros Sci. 2013;66:233-41.

20. Vermaak N, Mottura A, Pollock TM. Cyclic oxidation of high temperature coatings on new $\gamma^{\prime}$-strengthened cobalt-based alloys. Corros Sci. 2013;75:300-8.

21. Yan HY, Vorontsov VA, Dye D. Effect of alloying on the oxidation behaviour of $\mathrm{Co}-\mathrm{Al}-\mathrm{W}$ superalloys. Corros Sci. 2014;83:382-95.

22. Klein L, Killian M, Virtanen S. The effect of nickel and silicon addition on some oxidation properties of novel Co-based high temperature alloys. Corros Sci. 2012;69:43-9.

23. Makineni SK, Nithin B, Chattopadhyay K. Synthesis of a new tungsten-free $\gamma / \gamma^{\prime}$ cobalt-based superalloy by tuning alloying additions. Acta Mater. 2015;85:85-94.

24. Mikuszewski T, Tomaszewska A, Moskal G, Migas D, Niemiec D. Primary microstructure characterization of new type $\gamma-\gamma^{\prime} \mathrm{Co}-$ Al-W cobalt-based superalloys. Mater Eng. 2017;5:217-23.

25. Zenk CH, Neumeier S, Stone HJ, Goken M. Mechanical properties and lattice misfit of $\gamma-\gamma^{\prime}$ strengthened Co-base superalloys in the $\mathrm{Co}-\mathrm{W}-\mathrm{Al}-\mathrm{Ti}$ quaternary system. Intermetallics. 2014;55:28-39.

26. Suzuki A, Pollock TM. High-temperature strength and deformation of $\gamma / \gamma^{\prime}$ two-phase Co-Al-W base alloys. Acta Mater. 2008;56:1288-97.

27. Bauer A, Neumeier S, Pyczak F, Singer RF, Göken M. Creep properties of different $\gamma^{\prime}$-strengthened Co-base superalloys. Mater Sci Eng A. 2012;550:333-41.

28. Makineni SK, Samanta A, Rojhirunsakool T, Alam T, Nithin V, Singh AK, Banerjee R, Chattopadhyay K. A new class of high strength high temperature Cobalt based $\gamma-\gamma^{\prime}$ Co-Mo-Al alloys stabilized with Ta addition. Acta Mater. 2015;97:29-40.

29. Wanga P, Xiong W, Kattner UR, Campbell CE, Lass EA, Oleg Y, Kontsevoi OY, Olson GB. Thermodynamic re-assessment of the Al-Co-W system. Calphad. 2017;59:112-30. 